\title{
Multifunctional switches based on bis-imidazole derivative
}

\author{
ABDULLAH M A ASIRI ${ }^{1, *}$, GAMEEL A BAGHAFFAR ${ }^{1}$, KHADIJA O BADAHDAH ${ }^{1}$, \\ ABDULLAH G M AL-SEHEMI ${ }^{2}$, SALMAN A KHAN ${ }^{1}$ and ABEER A BUKHARI ${ }^{1}$ \\ ${ }^{1}$ Chemistry Department, Faculty of Science, King Abdul Aziz University, Jeddah 21413, \\ P.O. Box 80203, Saudi Arabia \\ ${ }^{2}$ Department of Chemistry, Teacher's College, King Khalid University, P.O. Box 249, Abha, \\ Saudi Arabia \\ e-mail: aasiri2@kau.edu.sa
}

MS received 17 December 2008; revised 24 June 2009; accepted 29 July 2009

\begin{abstract}
A multifunctional bis-imidazole derived from piperonal was prepared and found to have photo, thermo, solvato and peiezochromism with colour changes from pale green to deep blue. The multifunctionality colour changes and stability of the coloured species make the derivative candidates for various applications such as optical data storage. The photochromic properties and performance were found to be affected remarkably upon changing the solvent.
\end{abstract}

Keywords. Imidazole; free radical equilibrium; piezochromism; thermochromism; photochromism; solvatochromism.

\section{Introduction}

Many organic molecules which exhibit reversible conversion between two states when stimulated by an external input have been proposed and investigated. Based on those the, monomolecular photochromic switches, ${ }^{1-4}$ fluorescence switches,${ }^{5-8}$ chiral switches, ${ }^{9-12}$ redox switches ${ }^{13-18}$ and $\mathrm{pH}$ switches, ${ }^{19-21}$ metal functionalize switch, ${ }^{22}$ protonation switch, ${ }^{23}$ morphological switch $^{24}$ have been successfully reported. But the information processed by these two-state molecular switches is limited. In this context, the chemical systems which integrate several switchable functions into one single molecule have recently become the focus of research and will meet the requirement in the field of high density information process. To reach this multi-switchable goal, it is essential that the organic molecule can reversibly change its structures between more states in response to the combination of external signals such as photonic, chemical, electrochemical, or magnetic stimuli and generate readable outputs such as electronic or optical signals those reflect the molecular states. In this paper, we report a single molecule which is capable of integrating the effects of multiple stimuli and producing three switchable functions. It

*For correspondence is known that certain dimeric nitrogen-containing heterocyclic compounds such as dimeric NAD $(\mathrm{N}$ benzyldihydronicotinamide) are involved in some biological redox processes. ${ }^{25}$ On the other hand, triphenylimidazole dimers have also attracted attention because of the sensitivity of these compounds to light, heat and pressure. Hayashi and Maeda observed that upon oxidation with potassium ferricyanide in ethanolic solution, triphenylimidazole dimer $\mathbf{1}$ gave rise to violet colour which disappeared rapidly. The oxidation product was obtained as a pale violetcoloured powder, which turned deep violet in solution under UV irradiation. ${ }^{26}$ It has been suggested that the coloured species is a free radical, and EPR evidence for the existence of the radical was presented. ${ }^{27}$ It is now known that the oxidation product is a piezochromic dimer, which transforms to the photochromic dimer on dissolution in a solvent. In solution, the photochromic dimer exists in a photostationary equilibrium with its radical form.

Radical stability in these systems has been investigated by a number of workers with respect to the influence of substituents. ${ }^{28}$ It has been found that an electron-donating group on the phenyl ring will shift the photostationary state to the radical form. In continuation of some of our previous work, ${ }^{29,30}$ we synthesized multifunctional systems from carbazole (1) and chlorosubstitued benzaldehyde (2). 

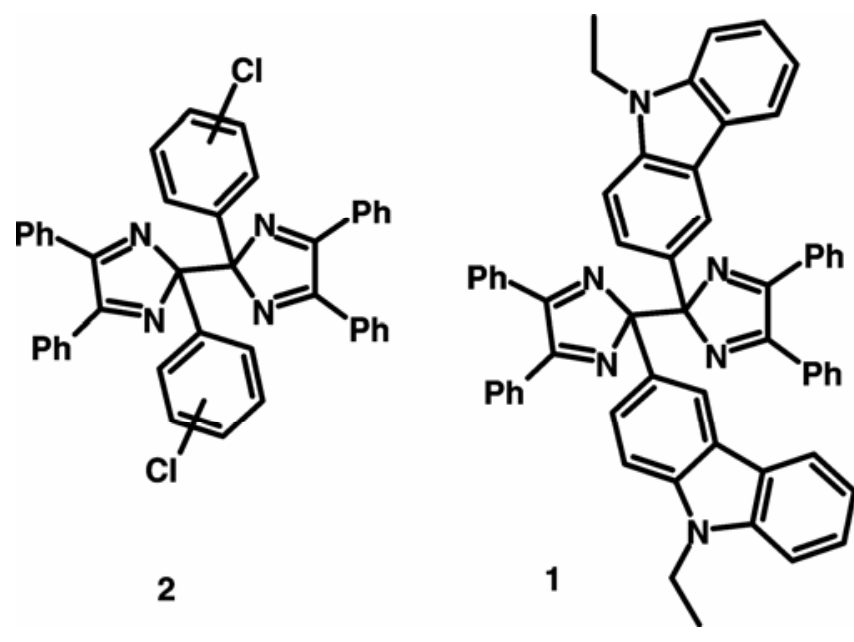

Compound 4 is a derivative of bis-imidazole, namely the derivative of bis-imidazole functionalized with piperonal.

\section{Experimental}

Melting points were determined on a ThomasHoover capillary melting apparatus and are uncorrected. IR spectra were taken as $\mathrm{KBr}$ disk on a Nicolet Magna 520 FTIR spectrometer. ${ }^{1} \mathrm{H}$ NMR were recorded in $\mathrm{CDCl}_{3}$ on a Bruker DPX 400 spectrometer using TMS as internal standard. UV-Vis spectra were recorded on a Shimadzu 260 spectrometer for solutions.

\subsection{Preparation of 2-benzo[1,3]dioxol-5-yl-4,5- diphenyl-1H-imidazole (3)}

In a round bottom flask fitted with a magnetic stirrer, benzil $(0.05 \mathrm{~mol})$, Piperonal aldehyde $(7.5 \mathrm{~g}$, $50.0 \mathrm{mmol})$ and ammonium acetate $(12.3 \mathrm{~g}$, $150 \mathrm{mmol})$ were dissolved in acetic acid $(100 \mathrm{ml})$. The mixture was heated under reflux in an oil bath for $1 \mathrm{~h}$ with stirring. After this time, the mixture was cooled to room temperature and filtered to remove any precipitate. Water $(500 \mathrm{ml})$ was added to the filtrate and the precipitate formed was collected. Recrystaliztion from ethanol afforded the imidazole 3.

White powder; yield $96.9 \%$; m.p.: $256 \cdot 2^{\circ} \mathrm{C}$; IR $v$ $\left(\mathrm{cm}^{-1}\right) ; 3026 \cdot 3(\mathrm{CH}$ aromatic stretch), $1598 \cdot 2(\mathrm{C}=\mathrm{N})$, $1480(\mathrm{C}=\mathrm{C}), 1338.7(\mathrm{C}-\mathrm{O})$ and $1239.1(\mathrm{C}-\mathrm{N}) .1 \mathrm{H}-$ NMR $\left(\mathrm{CDCl}_{3}\right) \delta ; 10.63(s, \mathrm{NH}), 8.13(d, \mathrm{CH}$ aromatic), $7.91(d, 4 \mathrm{CH}$ aromatic), $7.55(s, \mathrm{CH}$ aromatic), $7.36(d d, 4 \mathrm{CH}$ aromatic), 7.24 ( $d d, \mathrm{CH}$ aromatic), $6.70\left(d, \mathrm{CH}\right.$ aromatic) and $6.01\left(s, \mathrm{CH}_{2}\right)$.
2.2 Preparation of 2,2'-bis-benzo [1,3] dioxol-5$y l-4,5,4$ ', 5'-tetraphenyl- $1 \mathrm{H}, 2 \mathrm{H}$ - [1,2'] bisimidazolyl (4)

In a $1 \mathrm{~L}$ beaker, $\mathrm{KOH}(0.82 \mathrm{~g}, 14.7 \mathrm{mmol})$ was dissolved in $50 \mathrm{ml}$ of $95 \%$ ethanol. Imidazole $3(5.0 \mathrm{~g}$, $14.7 \mathrm{mmol}$ ) was added into the beaker. After the complete dissolution of imidazole $\mathbf{3}$, the reaction solution was placed in an ice bath and allowed it to cool to $5^{\circ} \mathrm{C}$. A freshly prepared solution of $\mathrm{K}_{3} \mathrm{Fe}(\mathrm{CN})_{6}(4.84 \mathrm{~g}, 14.7 \mathrm{mmol})$ was added dropwise to the stirring solution of the imidazole. The solution temperature was maintained below $10^{\circ} \mathrm{C}$. The solution turned violet and then produced a precipitate. The precipitate was collected by filtration and washed with $3 \times 25 \mathrm{~mL}$ of water and dried, to give the bis-imidazole 4 as a yellow powder; yield $11.7 \%$; m.p.: $192.8^{\circ} \mathrm{C}$; IR $v\left(\mathrm{~cm}^{-1}\right) ; 3026\left(\mathrm{CH}_{\text {aromatic stretch }}\right)$, $1601.9(\mathrm{C}=\mathrm{N}), 1481.1 \quad(\mathrm{C}=\mathrm{C}), 1247.6(\mathrm{C}-\mathrm{O})$ and $1039 \quad(\mathrm{C}-\mathrm{N}) . \quad{ }^{1} \mathrm{H}-\mathrm{NMR} \quad\left(\mathrm{CDCl}_{3}\right) \quad \delta ; \quad 8.14 \quad(d$, $\left.2 \mathrm{CH}_{\text {aromatic }}\right), 8.03\left(d, 2 \mathrm{CH}_{\text {aromatic }}\right), 7.99\left(d, \mathrm{CH}_{\text {aromatic }}\right)$, $7.93\left(d, 4 \mathrm{CH}_{\text {aromatic }}\right), 7.88\left(d, \mathrm{CH}_{\text {aromatic }}\right), 7.81(s$, $\left.\mathrm{CH}_{\text {aromatic }}\right), 7.64\left(d d, 2 \mathrm{CH}_{\text {aromatic }}\right), 7.45\left(d d, 2 \mathrm{CH}_{\text {aromatic }}\right)$, $7.33\left(\mathrm{~s}, \mathrm{CH}_{\text {aromatic }}\right), 7.34\left(\mathrm{dd}, 2 \mathrm{CH}_{\text {aromatic }}\right), 7.28(\mathrm{dd}$, $\left.5 \mathrm{CH}_{\text {aromatic }}\right), 7 \cdot 25\left(d, \mathrm{CH}_{\text {aromatic }}\right), 7 \cdot 24\left(d d, \mathrm{CH}_{\text {aromatic }}\right)$, $6.93\left(d, \mathrm{CH}_{\text {aromatic }}\right), 6.01\left(s, 2 \mathrm{CH}_{2}\right)$ and $5.94(s$, $\left.2 \mathrm{CH}_{2}\right) .{ }^{13} \mathrm{C}-\mathrm{NMR}\left(\mathrm{CDCl}_{3}\right) 168.0,148.26,148.2$, $147.56,147.46,146.6,145.9,137.6,134.9,134 \cdot 3$, $132.9,132 \cdot 7,131.9,131 \cdot 6,131 \cdot 1,129 \cdot 9 \cdot 129 \cdot 3$, $129 \cdot 0,128 \cdot 9,128 \cdot 7,128 \cdot 5,128 \cdot 3,128 \cdot 0,127 \cdot 9$, $127 \cdot 7,126 \cdot 6,127 \cdot 2,127 \cdot 1,126 \cdot 2,124 \cdot 4,122 \cdot 7$ $119 \cdot 1,111 \cdot 9,110 \cdot 8,109 \cdot 1,108 \cdot 6,108 \cdot 3,107 \cdot 5$, $107 \cdot 2,106 \cdot 2,101 \cdot 7,101 \cdot 3,101 \cdot 0,100 \cdot 9$.

\section{Results and discussion}

3.1 Synthesis of 2,2'-bis-benzo[1,3]dioxol-5-yl-4, 5,4', ' '-tetraphenyl- $1 \mathrm{H}, 2 \mathrm{H}$-[1,2'] bisimidazolyl (4)

The preparation of 2,2'-bis-benzo [1,3] dioxol-5-yl$4,5,4^{\prime}, 5^{\prime}$-tetraphenyl-1H, 2'H-[1,2'] bisimidazolyl 4 carried out by refluxing a solution of benzil, piperonal and ammonium acetate in acetic acid to give the 2-benzo [1,3] dioxol-5-yl-4, 5-diphenyl-1Himidazole 3. The oxidative dimerization was carried out using potassium ferricyanide to give the products $\mathbf{4}$, as shown in scheme 1 .

\subsection{Photochromism}

Irradiation of the solution of compound $\mathbf{4}$ in toluene and acetonitrile at $366 \mathrm{~nm}$ (medium pressure Mer- 
cury lamp) gave colour change from yellow to green. This colour change is due to the dissociation of the dimer 4 to form the free radical $\mathbf{5}$ as shown in scheme 2 .

Figure 1 shows the UV-Visible spectral changes of compound 4 in toluene before and after irradiation with UV light $(366 \mathrm{~nm})$ at different intervals of times table 1 .

\subsection{Thermochromism}

In toluene, the compound $\mathbf{4}$, was found to mainly in the radical form $\mathbf{5}$, which is colour. Upon heating, the colour disappeared due to the recombination of the radical to form the original dimer (scheme 3 ).

The compound 4 in acetonitrile showed no thermochromic properties. Figure 2 shows the UV-Vis spectral changes of compound 4 in toluene before and after heating at different intervals of times. Table 1 summarizes the maximum wavelength of the<smiles>O=Cc1ccc2c(c1)OCO2</smiles>

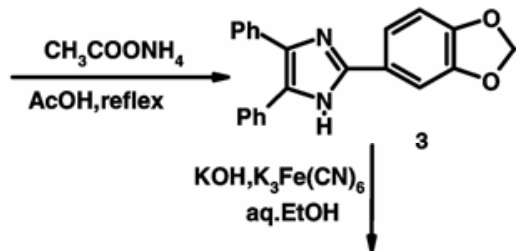<smiles></smiles>

Scheme 1.<smiles></smiles>

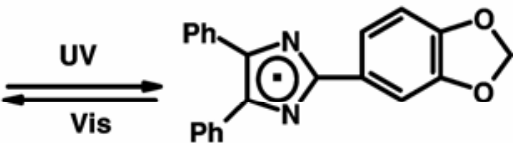

Scheme 2. radical 5 in two different solvents namely toluene and acetonitrile.

\subsection{Piezochromism}

Upon grinding of $\mathbf{4}$ in the solid state change of colour from pale-green to blue was observed due to the formation of the radical $\mathbf{5}$. When the coloured solid was kept in the dark, the colour disappeared as a result of the recombination of the radical as shown in scheme 4 .

\subsection{Solvatochromism}

The photochromic and thermochromic behaviour of compound 4 was recorded in two solvents of different polarity, i.e. toluene and acetonitrile (table 1).

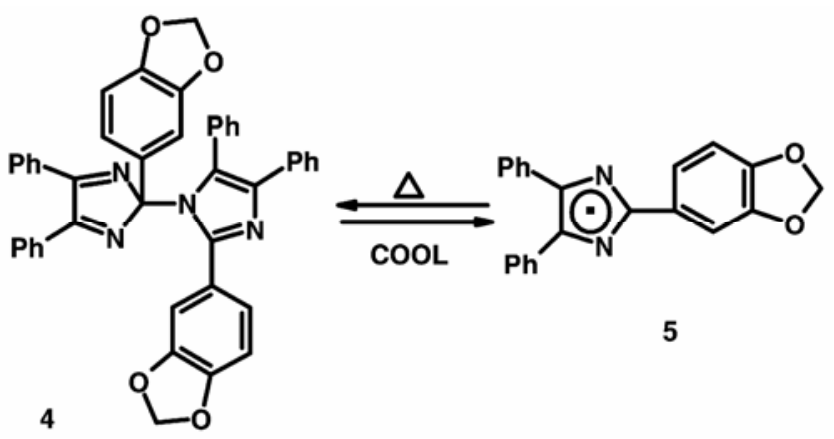

Scheme 3.

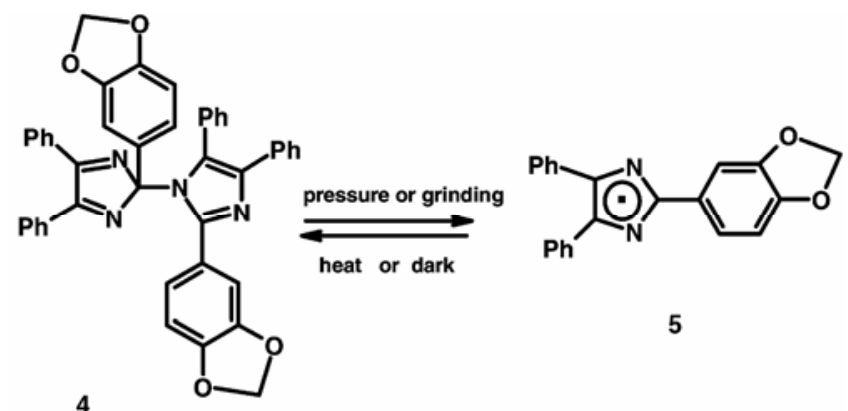

Scheme 4.

Table 1. Absorption wavelength of the coloured compound $\mathbf{5}$ after irradiation and heating.

\begin{tabular}{lcccccc}
\hline & \multicolumn{4}{c}{$\lambda_{\max }(\mathrm{nm})$} \\
\cline { 2 - 3 } Compound & \multicolumn{2}{c}{ Toluene } & & \multicolumn{2}{c}{ Acetonitrile } \\
\cline { 2 - 3 } \cline { 5 - 6 } & UV & Heating & & UV & Heating \\
\hline $\mathbf{5}$ & 675 & 670 & & 675 & - \\
\hline
\end{tabular}


Table 2. Kinetic data for photocolouration and heating of compound 4 in various solvent.

\begin{tabular}{|c|c|c|c|c|c|c|c|c|}
\hline \multirow[b]{3}{*}{ Compound } & \multicolumn{4}{|c|}{$t_{1 / 2}(\min )$} & \multicolumn{4}{|c|}{$K\left(\mathrm{~s}^{-1}\right)$} \\
\hline & \multicolumn{2}{|c|}{ Toluene } & \multicolumn{2}{|c|}{ Acetonitrile } & \multicolumn{2}{|c|}{ Toluene } & \multicolumn{2}{|c|}{ Acetonitrile } \\
\hline & UV & Heat & UV & Heat & UV & Heat & UV & Heat \\
\hline 4 & $4 \cdot 12$ & $5 \cdot 77$ & $0 \cdot 37$ & - & $0 \cdot 0028$ & $-0 \cdot 002$ & 0.031 & - \\
\hline
\end{tabular}

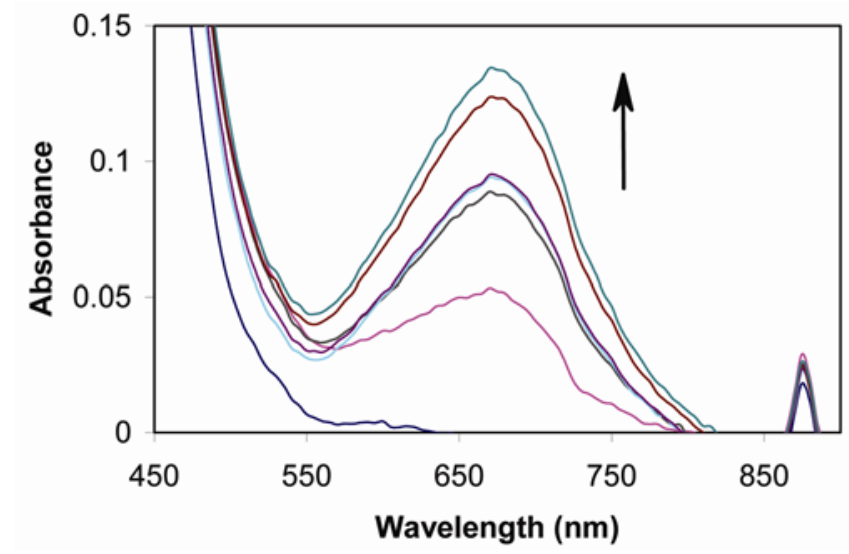

Figure 1. UV-Visible spectra of compound 4 before and after irradiation in toluene.

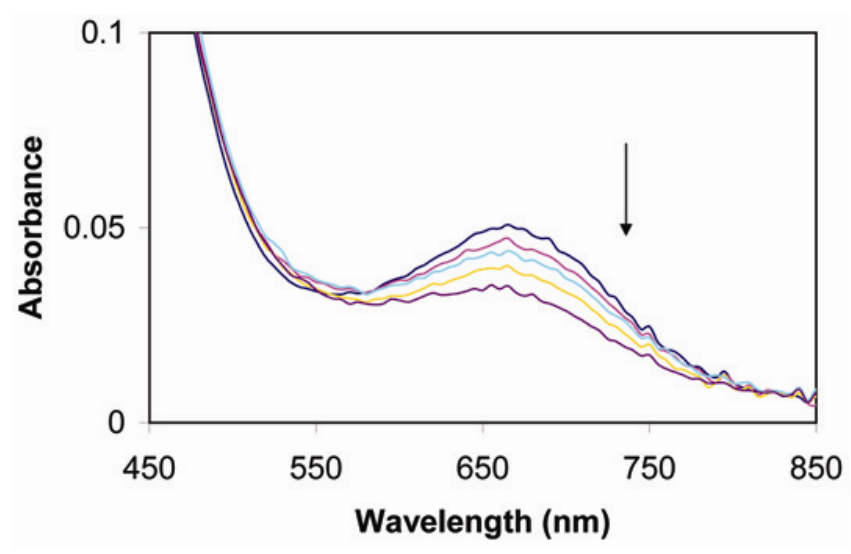

Figure 2. UV-Visible spectra of compound 4 before and after heating in toluene.

\subsection{Colouration kinetics}

A plot of $\ln \mathrm{A}$ vs time of irradiation or heating time gave a straight line indicating that both UV colouration and thermochromic behaviour obey first order rate equation. The colouration and bleaching data are summarized in table 2.

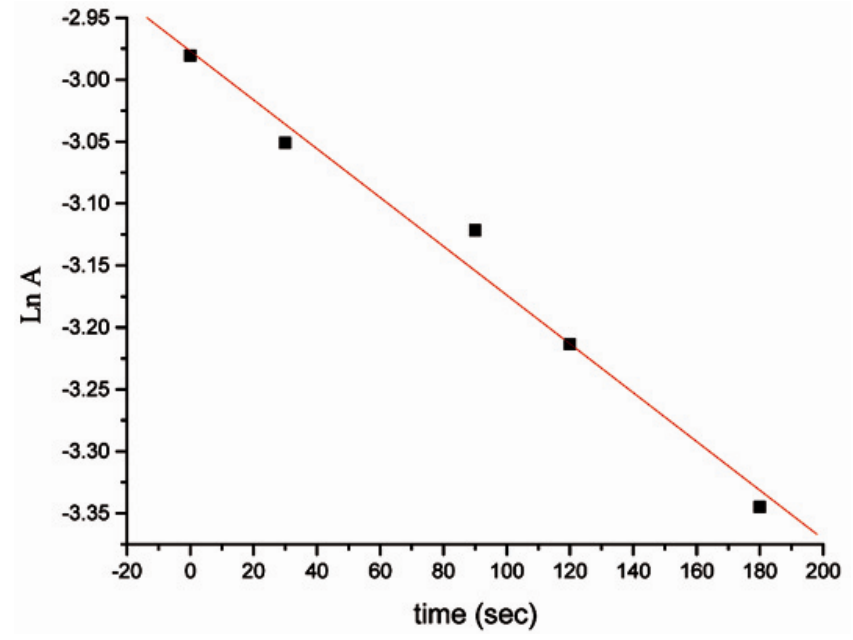

Figure 3. Plot of $\ln A$ vs time of compound 4 upon heating in toluene.

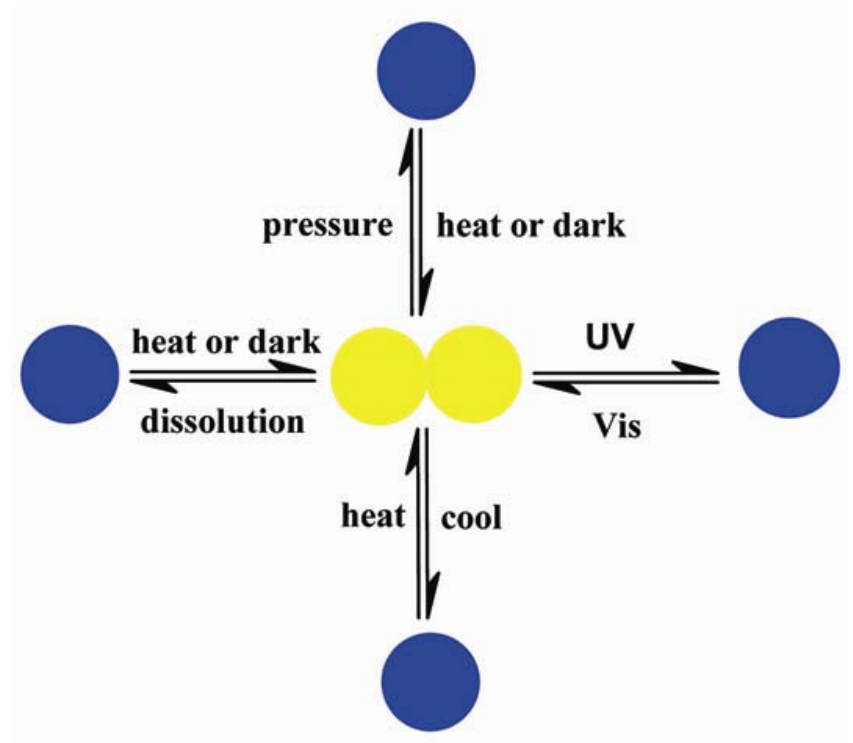

Figure 4. Representation of multifunctionality bisimidazol 4.

\section{Conclusion}

A multifunctional bis-imidazole derived from piperonal was prepared and found to exhibit photo, 
thermo, solvato and peiezochromism with colour changes from pale green to deep blue (figure 4). The multifunctionallity colour changes and stability of the coloured species make the derivative a candidate for applications in optical data storage.

\section{Acknowledgements}

The authors wish to thank King Abdul Aziz City for Science and Technology (KACST) for funding this research work via grant no. At-27-68.

\section{References}

1. Gust D, Moore T A and Moore A L 2001 Acc. Chem. Res. 3440

2. Nakano A, Yamazaki T and Osuka A 2000 Chem. Eur. J. 63254

3. Fujiwara T, Harada J and Ogawa K 2004 J. Phys. Chem. B108 4035

4. Harada J, Nakajima R and Ogawa K $2008 \mathrm{~J}$. Am. Chem. Soc. 1307085

5. Inada T, Uchida S and Yokoyama Y 1997 Chem. Lett. 321

6. Tsivgoulis G M and Lehn J-M 1996 Chem. Eur. J. 2 1399

7. Engeser M, Fabbrizzi L, Licchelli M and Sacchi D 1999 Chem. Commun. 1191

8. Rochford J, Denise A, Rooney and Mary T Pryce 2007 Inor. Chem. 467247

9. Zhou Y, Zhang D, Zhang Y, Tang Y and Zhu D 2005 J. Org. Chem. 706164

10. Feringa B L, van Delden R A, Koumura N and Geertsema E M 2000 Chem. Rev. 1001789

11. Pieraccini S, Masiero S, Spada G P and Gottarelli G 2003 Chem. Commun. 598
12. Rivado-Casas L, Sampedro D, Campos P J, Fusi S, Zanirato V and Olivucci M $2009 \mathrm{~J}$. Org. Chem. (in press)

13. Kaifer A E 1999 Acc. Chem. Res. 3262

14. Niema A and Rotello V M 1999 Acc. Chem. Res. 3244

15. Beer G, Niederalt C, Grimme S and Daub J 2000 Angew. Chem. Int. Ed. 393252

16. Fioravanti G, Haraszkiewicz N, Kay E R, Mendoza S M, Bruno C, Marcaccio M, Wiering P G, Paolucci F, Rudolf P, Brouwer A M and Leigh D A $2008 \mathrm{~J}$. Am. Chem. Soc. 1302593

17. Fukui M, Mori T, Inoue Y and Rathore R 2007 Org. Lett. 93977

18. Halim M, Tremblay M S, Jockusch S, Turro N J and Sames D 2007 J. Am. Chem. Soc. 1297704

19. Han M, Gao L, Lu Y and Wang K 2006 J. Phys. Chem. B110 2364

20. Badjic J D, Ronconi C M, Stoddart J F, Balzani V, Silvi S and Credi A 2006 J. Am. Chem. Soc. 1281489

21. Shiraishi $Y$, Tokitoh $Y$, Nishimura $G$ and Hirai $T$ 2005 Org. Lett. 72611

22. Klajn R, Fang L, Coskun A, Olson M A, Wesson P J, Stoddart J F and Grzybowski B A $2009 \mathrm{~J}$. Am. Chem. Soc. 1314233

23. Ratnala VR P, Kiihne S R, Buda F, Leurs R, Groot H J M and De-Grip W J 2007 J. Am. Chem. Soc. 129867

24. Ulrich S 2009 J. Lehn, J. Am. Chem. Soc. 1315546

25. Patz M, Kuwahara Y, Suenobu $T$ and Fukuzumi S 1997 Chem. Lett. 26567

26. Hayashi T and Maeda K 1960 Bull. Chem. Soc. Jpn. 33565

27. Hayashi T, Maeda K, Shida S and Nakada K $1960 \mathrm{~J}$. Chem. Phys. 321568

28. Cescon L A, Coraor G R, Dessauer R, Silversmith E F and Urban E J $1971 \mathrm{~J}$. Org. Chem. 362262

29. Asiri A M, Badahdeh K O, AlAmry K A and Bukhari A A 2005 Chemistry 25

30. Asiri A M, Badahdeh K O, AlAmry K A and Bukhari A A 2006 Pigment \& Resin Technol. 35200 